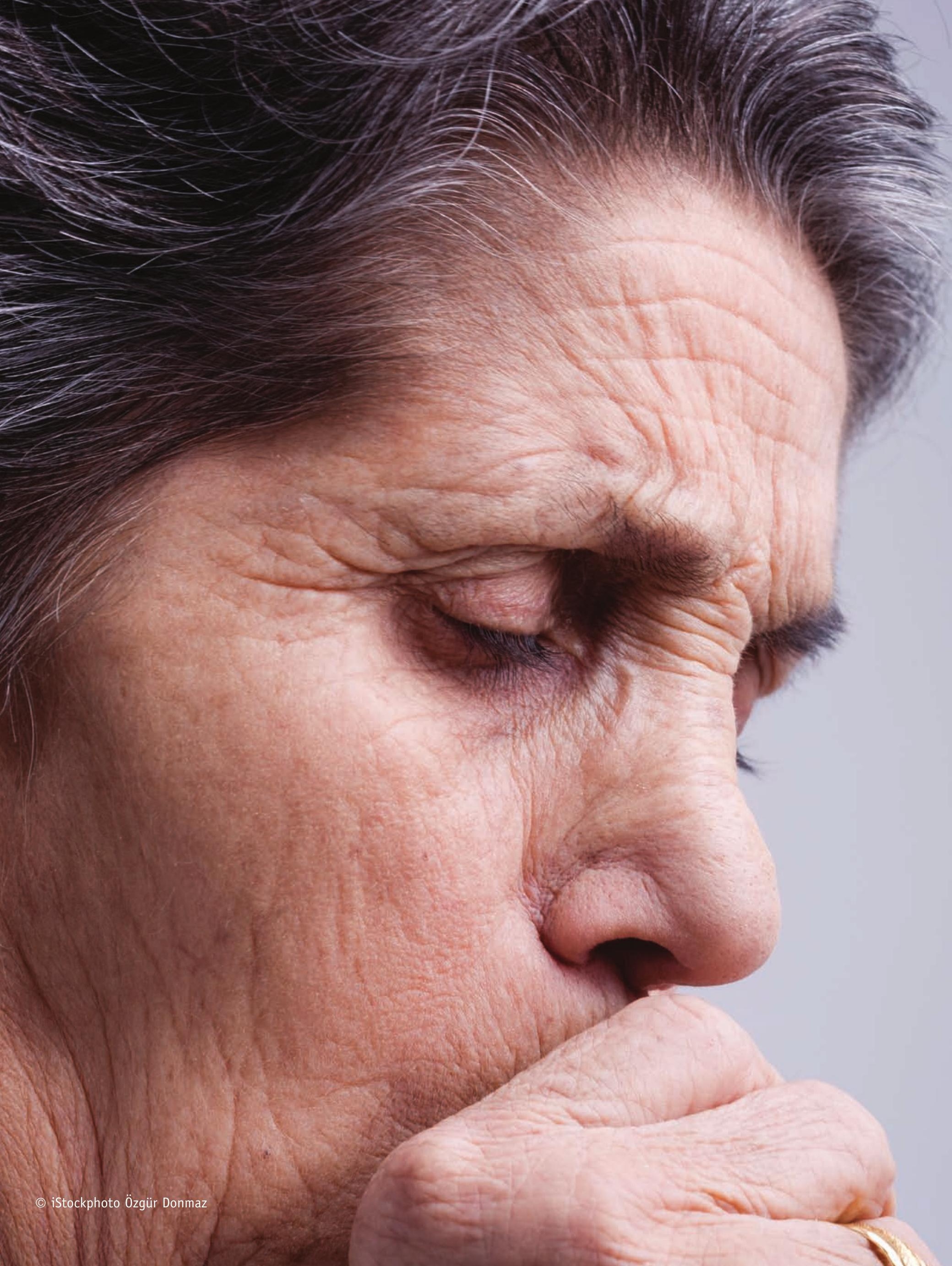




\section{Management of cough in adults}

\section{Educational aims}

1 To illustrate reasonable and costeffective management of cough, one of the most frequent reasons for primary care consultations.

1 To assist in the secondary care diagnosis and treatment of chronic cough as the solely presenting symptom if chest radiography and lung function tests remain inconclusive.

1 To emphasise the rational order starting with simple (noninvasive and costeffective) diagnostic procedures, graduating to complex, invasive and expensive (e.g. computed tomography and bronchoscopy) measures.

\section{Summary}

Cough is highly prevalent as a cumbersome presenting complaint for many patients. The symptom cough is elicited by a myriad of very different respiratory and nonrespiratory diseases. Symptomatic pharmacological treatment is of very limited efficacy. Presently, no new drug for cough in the pipeline has completed phase II development. Therefore, treating cough requires exact diagnosis for causal treatment. Cough is often the first (but not necessarily an early) symptom of life-threatening diseases, such as lung tumours or recurrent pulmonary embolism. Thus, in 2004, the German Respiratory Society published evidence-based guidelines on the management of cough. Acute and chronic cough were defined, and algorithms were provided for diagnostic workup. In 2010, the guidelines were updated (http://leitlinien.net). An abridged english version is also now available [1]. In this review, evidence-based recommendations (mostly weak evidence or consensus) from these guidelines are adapted into learning points.

Cough is both an important physiological reflex protecting the airways, and a frequent complaint associated with virtually all pulmonary and several extrapulmonary diseases. Cough is also a contributing factor in the spreading of infectious disease, such as tuberculosis. Moreover, (acute) cough due to the common cold is one of the most frequent causes of primary care consultations.

The reflex is characterised by complexity and plasticity, and is triggered by physical and chemical stimuli. Irritant receptors and C-fibre receptors are activated in the airways, pleura, pericardium and oesophagus. The impulse is then transmitted to the brainstem cough generator circuit via the vagus nerves. There is also a connection to the cortex, allowing voluntary control of both eliciting and, to a limited degree, inhibiting cough [2]. Efferent innervations reach the effector muscles (diaphragm, abdominal, intercostals, back, and muscles of the larynx and upper airway). Mucociliary clearance is the primary means of clearing the bronchial system. To a certain degree, cough can compensate for impaired mucociliary clearance (e.g. that caused by the effects of smoking). If mucociliary clearance is overwhelmed by aspiration, an intact cough reflex protects the lungs effectively. However, an impaired cough reflex, e.g. after stroke,

\section{P. Kardos}

Respiratory, Maingau Hospital, Frankfurt, Germany

Correspondence

$P$. Kardos

Scheffelstraße 33

D-60318 Frankfurt am Main Germany

Kardos@lungenpraxis-maingau.de

Competing interests None declared.

HERMES syllabus link: module C1.5 
results in life-threatening aspiration pneumonia. The clearing competence of the cough reflex depends on several conditions: obstruction of the airways, bronchial collapsibility, lung volumes, respiratory muscle and laryngeal function, and the amount and viscosity of the mucus [3].

Cough is productive (wet) if the amount of the daily expectoration is $\geqslant 30 \mathrm{~mL}$ (two tablespoons' worth). The phlegm can be mucous, serous, purulent or bloody. Bronchial casts can also be produced.

The cough reflex arc consists of five parts: 1) cough receptors; 2) afferent nerves; 3) brainstem cough generator circuit; 4) efferent nerves; and 5) effector organs (muscles).

Hypersensitivity of the cough nociceptors elicits pathological cough. Numerous respiratory and other diseases cause cough nerve hypersensitivity and thus, produce cough. In a considerable number of clinical cases, however, only cough nerve sensitivity is affected without another "specific" cause. Such patients are suffering from idiopathic cough.

\section{Classification and frequent causes of cough}

The myriad of different respiratory and other diseases eliciting cough requires classification both for diagnostic workup and treatment (tables 1 and 2).

\section{Table 1 Classification of pulmonary causes of cough}

\begin{tabular}{|c|c|}
\hline Acute ( $\leqslant 8$ weeks) & Chronic ( $>8$ weeks) \\
\hline $\begin{array}{l}\text { Diseases of the lower airways } \\
\text { Asthma }\end{array}$ & $\begin{array}{l}\text { Diseases of the lower airways and lung } \\
\text { parenchyma }\end{array}$ \\
\hline Aspiration (commonly children aged 1-3 yrs) & Chronic (nonobstructive) bronchitis and COPD \\
\hline Inhalation intoxication (accidents and fire) & Asthma and other eosinophilic diseases \\
\hline \multirow[t]{2}{*}{ Post-infectious cough } & Lung tumours \\
\hline & Infectious diseases \\
\hline $\begin{array}{l}\text { Diseases of the lungs and pleura } \\
\text { Pneumonia }\end{array}$ & $\begin{array}{l}\text { DPLD (systemic diseases with diffuse lung } \\
\text { involvement) }\end{array}$ \\
\hline Pleurisy & Aspiration and RADS \\
\hline Pulmonary embolism & Bronchiectasis and cystic fibrosis \\
\hline \multirow[t]{2}{*}{ Pneumothorax } & Bronchomalacia \\
\hline & Rare, localised disease of the tracheobronchial tree \\
\hline
\end{tabular}

\section{Table 2 Classification of extrapulmonary causes of cough}

\begin{tabular}{ll}
\hline Acute ( $\leqslant \mathbf{8}$ weeks) & Chronic ( $>\mathbf{8}$ weeks) \\
Diseases of the upper airways & Diseases of the upper airways \\
Infectious disease of the upper airways, mostly viral & Chronic rhinitis, sinusitis, pharyngitis \\
infection (common cold) & and laryngitis \\
Allergic disease & Vocal cord dysfunction \\
Cardiac disease with acute pulmonary congestion & Obstructive sleep apnoea? \\
& Gastro-oesophageal reflux disease \\
& Drug-induced cough \\
& ACE inhibitors \\
Others \\
ACE: angiotensin-converting enzyme. & Cardiac diseases \\
& Any including pulmonary congestion \\
& Endocarditis
\end{tabular}




\section{Acute and chronic cough}

Cough as a symptom is attributed to distinct diseases and is categorised as either acute (lasting $\leqslant 8$ weeks) or chronic (lasting $>8$ weeks). Of course, these limits are arbitrary. Acute cough (due to common cold) usually lasts only 2-3 weeks. Various acute infections, (e.g. Mycoplasma pneumoniae and adenoviruses), however, can elicit cough lasting $\leqslant 8$ weeks; for example, Bordetella pertussis can cause cough lasting $\leqslant 3$ months. In otherwise healthy individuals, acute infections of the upper and/or lower airways, the most common cause of cough, are self-limiting. Medical history and physical examination are usually sufficient in the diagnosis, and over-the-counter (OTC; i.e. nonprescription) remedies for the treatment. However, a few special circumstances require immediate, full diagnosis of acute cough (table 3).

In contrast, immediate diagnostic work-up is essential in all patients presenting with chronic ( $>8$ weeks duration) cough; a chest radiograph and lung function test should be performed immediately. This is consistent with the recommendations in all published guidelines on cough [4-7].

If the chest radiograph proves inconclusive, the lung function test is unremarkable and cough is the only presenting symptom, it will always be difficult to establish the diagnosis. The

\section{Table 3 Circumstances requiring an immediate investigation of acute cough}

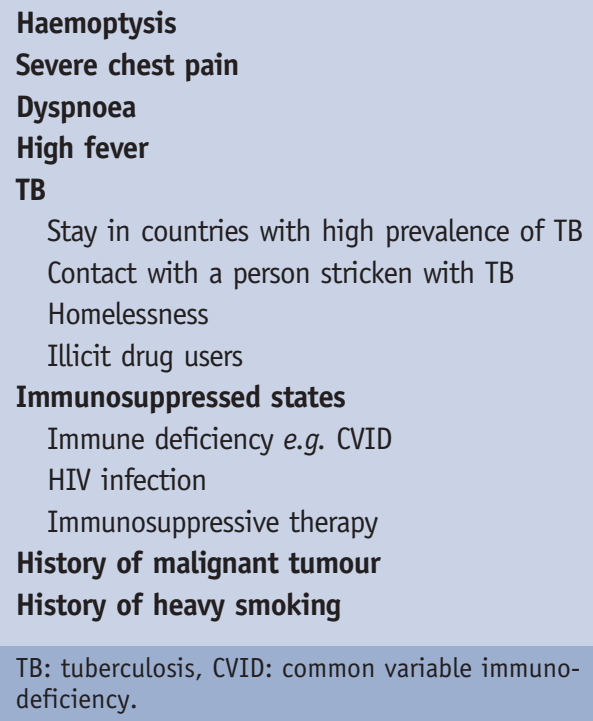

TB: tuberculosis, CVID: common variable immunodeficiency.

\section{Table 4 Most frequent causes of chronic cough without definite} chest radiography or lung function

$\begin{array}{ll}1 & \text { Cough due to upper airway disease } \\ 2 & \text { Cough-variant asthma } \\ 3 & \text { Gastro-oesophageal reflux disease } \\ (4) & \text { (Taking ACE antagonist medication) }\end{array}$

ACE: angiotensin-converting enzyme.

most common causes in the literature $[5,6$, 8-10] are shown in table 4.

\section{What are common causes of acute cough?}

Enhancing the cough nerve sensitivity following diseases can cause acute cough.

\section{Acute, self limiting viral infections of the upper and lower airways}

Common cold is the most common cause of cough and usually subsides spontaneously, in otherwise healthy persons, after 2-3 weeks [11].

\section{Upper airways allergic disease}

Hay fever, and intermittent or persistent allergic rhinitis, often in combination with sinusitis, conjunctivitis, pharyngitis and laryngitis, can also trigger acute cough. Itchy eyes and throat are usually characteristic of these diseases [12].

\section{Intermittent asthma}

Intermittent asthma, either allergic or due to infection, can cause acute cough.

\section{Aspiration}

Aspiration of a foreign body, most commonly in 1-3-yrold children, as well as in elderly, fragile patients, triggers acute cough with expectoration of the foreign body, or permanent bronchial obstruction with consecutive chronic cough.

\section{Learning points 1}

- Distinguish between acute ( $\leqslant 8$ weeks duration) and chronic cough ( $>8$ weeks); history and physical exam are usually adequate for diagnostic workup of patients with acute cough.

- Chronic cough patients need immediate further diagnostic measures (usually chest radiography and spirometry ). If they prove inconclusive, check for upper airway disease, variant asthma or gastro-oesophageal reflux disease. 


\section{Learning points 2}

- In otherwise healthy persons, common cold-related cough is self-limiting, usually lasting 2-3 weeks. OTC medication is appropriate. Antibiotics do not influence the natural history of this disease.

- In the case of acute inhalative intoxication, immediately prescribe high-dose inhaled corticosteroid ( $\leqslant 100$ puffs in $24 \mathrm{~h}$ ).

- Breathlessness, palpitation and acute cough are indicative of left heart failure, AV block and/or pulmonary embolism.

\section{Acute inhalative intoxication}

Workplace accidents, fires, and solvent or glue sniffing can lead to a toxic lung oedema, acute interstitial pneumonia and bronchiolitis with reemergence of cough, often after a discomfortand cough-free interval of 6-48 h. Immediate high-dose inhaled corticosteroid treatment should be initiated ( $\leqslant 100$ puffs in $24 \mathrm{~h}$ ).

\section{Post-infectious cough}

Postinfectious cough persists $>3$ weeks after an acute, often viral airway infection and resolves after $<8$ weeks. Epithelial damage after B. pertussis or M. pneumoniae infection, or a transient increase in bronchial hyperresponsiveness (BHR), later subsiding spontaneously, are responsible for postinfectious cough. In the latter case, a short course of asthma treatment (inhaled corticosteroids or $\beta_{2}$-adrenergics [4]) is effective.

Persistent BHR with consequent chronic cough without airflow obstruction is described as coughvariant asthma (see later). In this case, long-term inhaled corticosteroid treatment is required.

\section{Pneumonia}

Pneumonia should be considered as a cause of acute cough.

\section{Pleurisy}

Pleurisy is also a possible cause of acute cough.

\section{Pulmonary embolism}

$50 \%$ of patients with acute pulmonary embolism present with a cough [13].

\section{Pneumothorax}

All forms of pneumothorax can be accompanied by a dry cough.

\section{Acute heart failure with pulmonary congestion}

Acute left heart failure (including lung oedema) can trigger both cough and bronchial obstruction
$[14,15]$. Bradycardia associated with acute emerging atrioventricular (AV) block II-III can greatly reduce stroke volume, eliciting pulmonary congestion and cough. Atrial premature beats can elicit acute cough [16].

\section{What are the causes of chronic cough?}

Enhancing cough nerve sensitivity following diseases can cause chronic cough.

\section{Chronic bronchitis}

The World Health Organization defines chronic (nonobstructive) bronchitis as the presence of cough and phlegm on most days over a period of $\geqslant 3$ months during two consecutive years without other causes. Many patients suffering from chronic cough meet these criteria. From a therapeutic point of view, this diagnosis is only useful if an obvious cause (i.e. smoking or workrelated exposures) can be identified, cessation is possible and other causes of chronic cough have thoroughly been excluded. Though long-standing smokers frequently suffer from, but rarely complain of, cough and phlegm, chronic bronchitis is seldom a reason to attend a cough clinic.

\section{Chronic obstructive pulmonary disease}

By definition, patients with the chronic obstructive bronchitis phenotype of chronic obstructive pulmonary disease (COPD) are suffering from cough and phlegm. Chronic cough is a common symptom of COPD. In contrast to simple chronic bronchitis (see earlier), not fully reversible airflow limitation, as measured by spirometry, is the condition sine qua non for the diagnosis of COPD.

\section{Asthma and other eosinophilic respiratory disease}

Asthma is often responsible for chronic cough [17]. Dry cough can elicit or worsen an asthma attack.

Cough-variant asthma is characterised by dry cough and BHR. Wheezing, dyspnoea and bronchial obstruction are absent. Chronic cough with proven BHR can only be confirmed as variant asthma if asthma treatment (inhaled corticosteroids or $\beta_{2}$-adrenergics) eliminates the cough [10, 18-24].

Eosinophilic bronchitis is characterised by chronic cough and sputum eosinophilia in the 
absence of BHR. It is responsive to inhaled corticosteroid treatment $[25,26]$.

\section{Lung tumours}

Cough is the most common presenting symptom of lung tumours [27]. If a patient presenting with chronic cough (i.e. lasting $>8$ weeks) is not taking an angiotensin-converting enzyme (ACE) inhibitor, chest radiography should be performed immediately. Furthermore, in order to exclude a lung tumour, each patient with unexplained chronic cough should have a bronchoscopy at the end of the diagnostic algorithm (fig. 2).

\section{Cough due to upper airway disease}

Chronic rhinitis and sinusitis (rhino-sinusitis) [28] are often associated with posterior (i.e. postnasal drip) and/or anterior mucopurulent drainage, nasal stuffiness, facial pain, pressure, and/or fullness and decreased sense of smell. Chronic rhino-sinusitis can occur with or without nasal polyposis and allergic fungal rhinosinusitis, respectively.

Chronic pharyngitis and laryngitis [29] and chronic affections of the external auditory canal [30] can also cause chronic cough.

\section{Vocal cord dysfunction}

Recurrent voluntary inspiratory (sometimes also expiratory) adduction of the vocal cords can elicit throat clearing, dry cough, wheezing and dyspnoea. Vocal cord dysfunction can mimic asthma and often affects younger women [31].

\section{Gastro-oesophageal reflux disease}

Cough is triggered either by reflex, through reflux to the pharynx and larynx (laryngopharyngeal reflux), or microaspirations [32] of aerosolised gastric juice. Cough due to reflux can occur with or without heartburn [9] and does not necessarily coincide with reflux oesophagitis (nonerosive reflux disease). Thus, the gold standard of the reflux diagnosis is a triplesensor, 24-h $\mathrm{pH}$ probe and impedance $\mathrm{pH}$ probe. The latter allows diagnosis of both acid and weakly acid reflux. Thus, aerosolised gastric juice, which probably plays a crucial role, can be measured directly by pharyngeal $\mathrm{pH}$ probe. Since $\mathrm{pH}$ probes are of limited sensitivity, frequently not available and poorly tolerated, high dose $(2 \times 40 \mathrm{mg})$ proton pump inhibitor treatment over the course of $\leqslant 3$ months can be carried out as an alternative, thereby confirming or excluding the diagnosis of reflux cough [33] (fig. 2). However, unequivocal evidence for the efficacy of acid suppression from randomised controlled trials is lacking. In certain cases, surgical treatment (fundoplicatio) can be performed [34, 35], but no evidence-based selection criteria for surgery are yet available.

\section{Drug-induced cough}

Approximately $10 \%$ of women and $5 \%$ of men cough while taking ACE inhibitor medication [36], which increases cough reflex sensitivity. The therapeutic (antihypertensive, cardiac or nephroprotective) effects of an ACE inhibitor treatment can be replaced by angiotensin II receptor antagonists, which do not cause cough more frequently than placebo. For other drugs inducing cough, information is available at www.pneumotox.com

\section{Infections}

In adults, pertussis is a rare cause of chronic cough, but has been described even without a preceding phase of acute infection. In particular, patients with recent contact with persons suffering from acute whooping cough should be checked for antibodies. However, interpretation of the results is difficult. After the acute exudative phase of infection (taking $\leqslant 10$ days) a direct culture of Bordetella is no longer possible and antibiotics will have no effect on cough or on the natural history of the infection.

Chronic cough is a typical symptom of tuberculosis, and was one of its key diagnostic criteria in the pre-radiography era.

\section{Chronic cough due to heart disease}

Aside from chronic left heart failure (cough generally occurs upon physical exertion or prone position), AV block II-III, endocarditis [37] and cardiac arrhythmia [38, 39] can cause pulmonary congestion-related chronic cough. Moreover, chronic cough as a sideeffect of cardiac drugs, including ACE inhibitors, $\beta$-blockers (in patients with BHR) and amiodarone (eliciting alveolitis) has to be considered.

\section{Diffuse parenchymatous lung disease and systemic diseases with diffuse lung involvement}

In addition to dyspnoea, dry cough is the most common symptom of diffuse parenchymatous 


\section{Table 5 Chronic or deteriorating cough in patients with diffuse parenchymatous lung disease or autoimmune disease}
1 Due to the lung involvement itself (e.g. Sjögren's syndrome, Wegener's disease, systemic sclerosis, Churg-Strauss syndrome, idiopathic interstitial pneumonias and sarcoid)
2 Due to the treatment (drug induced cough: methotrexate, cyclophosphamide)
3 Due to infections in the immunocompromised host

lung disease (DPLD). Some forms of diffuse parenchymatous lung disease cause cough at such an early stage that the DPLD can be missed by conventional chest radiography. Thus, an apparently "normal" chest radiograph and spirometry do not rule out early lung disease with cough. A high-resolution computed tomography (HRCT) scan can establish the diagnosis.

Most systemic autoimmune disease can develop lung involvement and cause cough (e.g. Sjögren's syndrome, systemic lupus erythematosus, rheumatoid arthritis, systemic sclerosis and vasculitides). Chronic cough in DPLD, however, can also be due to the treatment or infection.

\section{Cough due to inhalative events}

Chronic cough is caused if an aspirated foreign body becomes trapped in the bronchial system (usually in children 1-3 yrs of age), or due to chronic recurrent aspiration of food (liquids) resulting from dysphagia in underlying neurological conditions (e.g. bulbar paralysis, Parkinson disease [40] and myasthenia gravis). Other causes include tracheal-oesophageal fistula, malformations, neck dissection (head and neck cancer) and regurgitation in heavy gastrooesophageal reflux disease

Reactive airways dysfunction syndrome (RADS) occurs following shortterm, intense inhalation of vapours, smoke or gases [41] (usually due to accidents in the workplace) and often develops into difficult asthma.

\section{Non-cystic fibrosis bronchiectasis and tracheobronchomalacia}

Bronchiectasis can be missed on chest radiography. The gold standard for diagnosis is HRCT. Bronchiectasis usually causes productive cough with voluminous secretion, and often haemoptysis.

Tracheobronchomalacia elicits chronic cough due to contact between the anterior and posterior wall of the bronchus intermedius or the trachea $[42,43]$.

\section{Cystic fibrosis}

Cystic fibrosis is an autosomal recessive inherited disease. Abortive forms can manifest in adulthood for the first time through cough, bronchial infections and bronchiectasis.

\section{Isolated orphan airways disease} Isolated orphan airways disease usually emerges in patients $>40$ yrs of age. It can lead to expiratory bronchial collapse and irreversible central obstruction of the airways. Coughing is frequently the main symptom (table 6).

\section{Sleep apnoea}

Sleep apnoea patients often complain of chronic cough [44].

\section{Psychogenic (habit) cough}

By definition, the sensitivity of the cough reflex is not increased in patients with psychogenic

\section{Table 6 Rare isolated disease of the tracheobronchial tree}

$\begin{array}{ll}\text { Disease } & \text { Comments } \\ \begin{array}{l}\text { Tracheobronchomegaly (Mounier-Kuhn syndrome) } \\ \text { Tracheobronchial amyloidal infiltration }\end{array} & \begin{array}{l}\text { Commonly in male patients } \\ \text { Local infiltration of the central airways (possibly } \\ \text { the larynx) by AL amyloid }\end{array} \\ \begin{array}{l}\text { Relapsing polychondritis } \\ \text { Tracheobronchopathia osteochondroplastica }\end{array} & \begin{array}{l}\text { Autoimme inflammatory disease } \\ \text { Heterotopic ossification }\end{array} \\ \text { Juvenile recurrent respiratory papillomatosis } & \begin{array}{l}\text { Adolescents, young adults, casued by human } \\ \text { papilloma virus }\end{array} \\ \text { AL: amyloid light chain. } & \end{array}$




\section{Table 7 Frequent mistakes in the diagnostic work-up of cough}

\begin{tabular}{|c|c|}
\hline 1 & Extensive diagnostic work-up performed in patients taking ACE inhibitors \\
\hline 2 & Trivialisation of cough in smokers without diagnostic workup \\
\hline 3 & Extrapulmonary causes (ENT, gastric, neurological or cardiac) are disregarded \\
\hline 4 & $\begin{array}{l}\text { Change of the established sequence of examinations without reason, e.g. performing HRCT } \\
\text { before BHR was tested }\end{array}$ \\
\hline 5 & No bronchoscopy though cause of cough was not determined. \\
\hline 6 & Multiple causes overlooked \\
\hline 7 & Psychogenic cough diagnosed, lung tumour overlooked \\
\hline
\end{tabular}

cough, but this is difficult to measure reliably. There is always a risk of misdiagnosis of multicausal or idiopathic cough as psychogenic cough.

\section{Chronic idiopathic cough}

Despite extensive diagnostic procedures, underlying causes (e.g. reflux, asthma, etc.) of the increased sensitivity of the cough reflex (as measured by standardised capsaicin or citric acid testing) cannot be determined in $\leqslant 18 \%$ of patients with chronic persistent cough (females: males $=2: 1$ ) [45].

\section{Diagnosis of cough}

Applying diagnostic algorithms frequently allows for a provisional diagnosis, which must be confirmed by successful treatment. Failure can, therefore, require continued investigation based on the algorithm. Multicausal cough requiring combination treatment also has to be considered. Figures 1 and 2 show algorithms for the diagnosis of acute and chronic cough, respectively.

\section{Symptomatic treatment of cough}

Causal treatment should always be sought. However, if this approach is impossible (e.g. acute viral respiratory infection) or would only prove effective in a delayed manner (e.g. tuberculosis), symptomatic treatment can be considered instead of, or complementary to, causal treatment of cough. Symptomatic treatment targets one or several of the five parts of the cough reflex arc. Effects can be

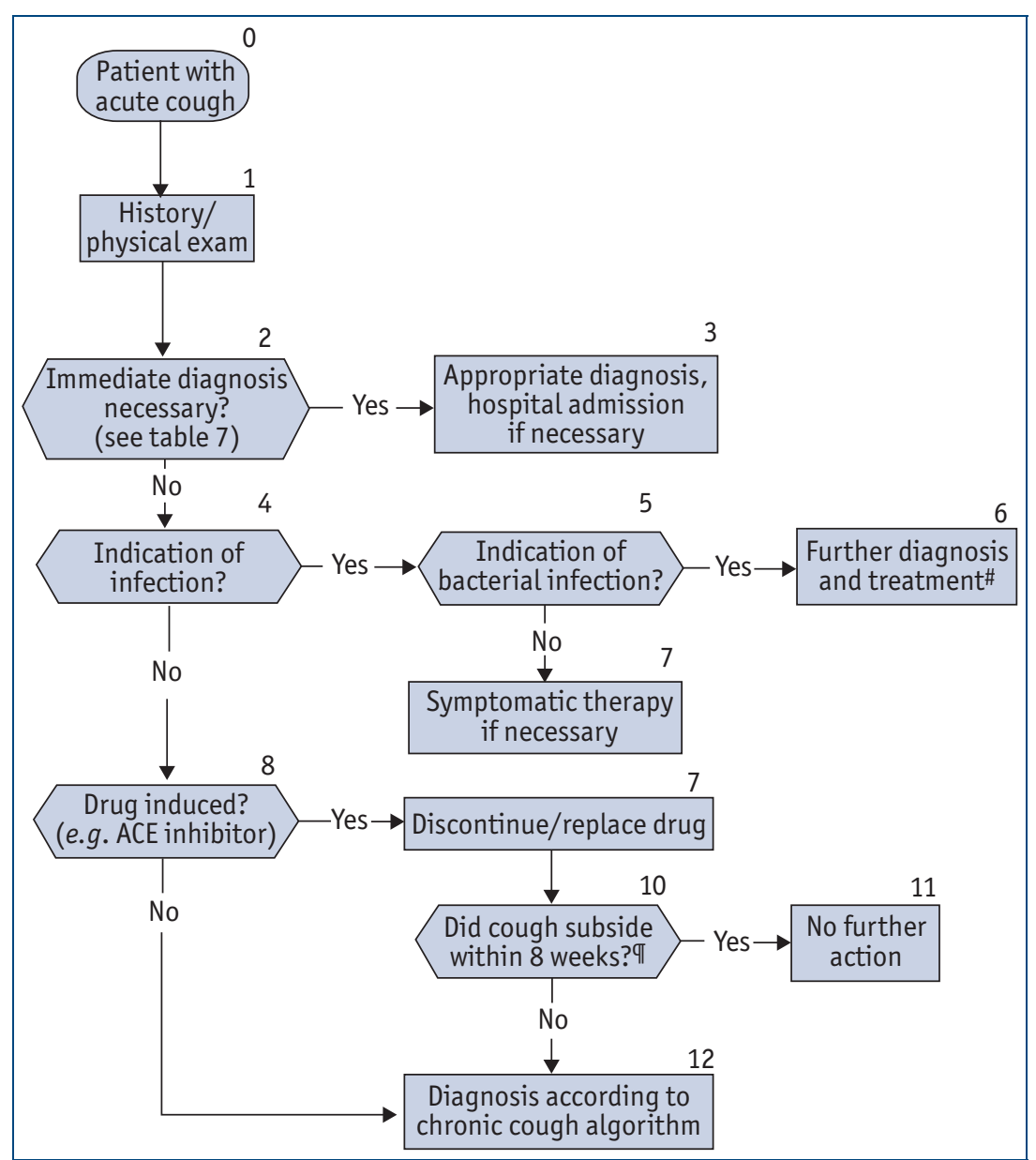

\section{Figure 1}

Clinical algorithm for the diagnosis of acute cough. Cough can persist for $\leqslant 8$ weeks after an acute infection subsides (post-infectious cough). Except for special circumstances (table 3), further examination according to the algorithm for chronic cough is only necessary after 8 weeks (box 12). \#: in otherwise healthy patients, antibiotics are not beneficial even in cases of purulent (green or yellow) sputum [46]; they are only recommended in comorbid or elderly patients with sputum purulence. ": caveat is remittent small pulmonary emboli with episodes of remittent cough, palpitations, breathlessness; slight haemoptysis may also occur. Modified from [1] with the publisher's permission. 


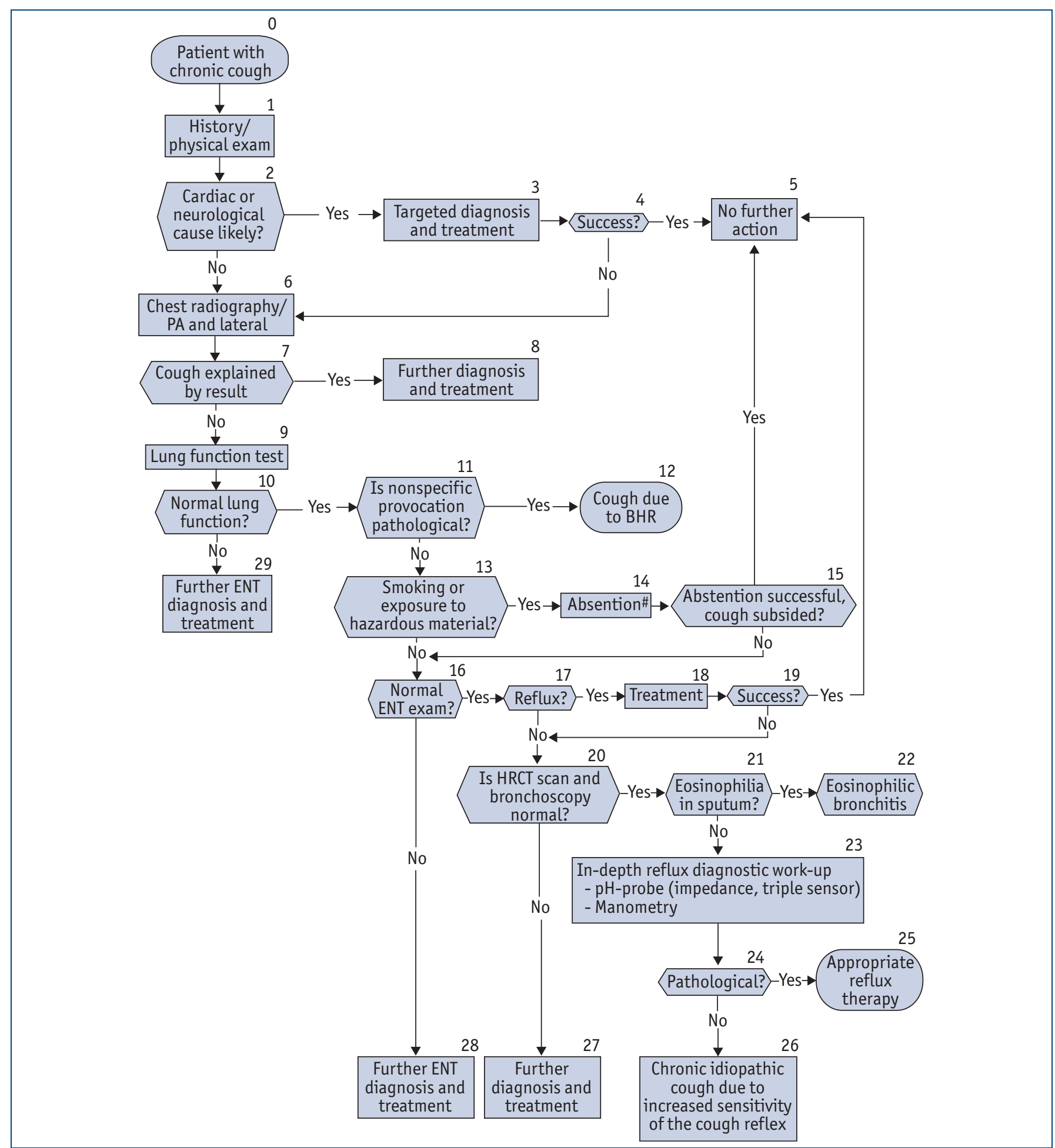

Figure 2

Clinical algorithm for the diagnosis of chronic cough. Every patient with unexplained chronic cough must have a bronchoscopy performed by the end of the diagnostic algorithm. If a patient complains of cough lasting $>8$ weeks, diagnostic workup should be initiated immediately. The first steps consist of collecting the patients' medical history and a physical exam (box 1). If a (primarily) cardiac or neurological cause (e.g. Parkinson syndrome or stroke) of cough is suspected, appropriate diagnostic workup must be initiated (box 3). Establishing the cause of chronic cough is challenging if neither the chest radiograph, nor the lung function test prove conclusive. If bronchial hyperresponsiveness (BHR) can be established by nonspecific inhalative provocation test (box 11), the cough can be treated as probable variant asthma. In smokers with inconclusive chest radiography and normal lung function, smoking-related chronic, nonobstructive bronchitis is the most likely cause of cough. Therefore, a period of smoking cessation is recommended before further diagnostic workup is initiated (box 14). If smoking cessation fails, or abstention remains unsuccessful after 4 weeks, diagnostic workup according to the algorithm 


\section{Figure 2 legend continued}

should be continued. Provided their chest radiography proves negative, patients with cough and heartburn can be provisionally diagnosed with suspected gastro-oesophageal reflux disease. Proton pump inhibitor (PPI) treatment can commence. In the case of remarkable gastroenterological history, one should proceed according to current gastroenterological recommendations. If, after as long as 3 months high-dose PPI treatment does not resolve the symptoms, continue the algorithm (including high-resolution computed tomography (HRCT) and bronchoscopy; box 20). If the cause of the cough remains unclear, extensive and targeted gastroenterological diagnosis should be performed. This includes endoscopy, oesophageal manometry and triple sensor pH-probe (or impedance for both acid and weakly acid reflux; box 23). At this point, the indication for surgery (fundoplicatio) can be assessed as well. Also, the most commonly missed diagnoses should be considered: early-stage, diffuse parenchymatous lung disease not yet evident on chest radiography, eosinophilic bronchitis (eosinophil cell count in the sputum >3\%; box 21) and a psychogenic cough (rare in adults) should all be taken into account. In some patients, the cause of chronic cough will remain unclear despite exhausting the available diagnostic tools. In this case, the patient suffers from chronic idiopathic cough, where the source of an increased sensitivity of the cough reflex cannot be established (box 26). PA: postero-anterior; ENT: ear, nose and throat; HRCT: high-resolution computed tomography. ${ }^{\#}$ : based on clinical suspicion, changes in severity andlor characteristics of cough, the patient may require immediate bronchoscopy, thus ignoring the steps of the algorithm. Modified from [1] with the publisher's permission.

protussive (increasing cough and expectoration) or antitussive.

\section{Physiotherapy of cough}

Despite being clinical routine in both hospital and outpatient care [47], as well as in rehabilitation, evidence for the efficacy of physiotherapy for cough is lacking. Physiotherapy aims to: 1) increase expectoration using effective coughing techniques for patients with productive but ineffective cough; 2) suppress voluntarily nonproductive cough; and 3) instruct patient in the use of physiotherapeutic equipment improving expectoration, such as Acapella ${ }_{\mathbb{B}}$ (DHD Healthcare, Wampsville, NY, USA), Flutter ${ }^{\circledR}$ (Desitin/ Scandipharm VarioRaw SA, Birmingham, AL,

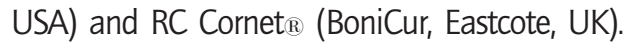

\section{Pharmacotherapy}

Expectorants reduce irritation of the cough receptors by accumulated mucus through "coughing up", and represent the most common medication used for respiratory diseases in Germany (e.g. ambroxol and N-acetylcysteine). Because of the lack of appropriate methods, effectiveness is difficult to assess. Regarding relative effectiveness of different expectorants, conflicting or inconsistent evidence exists throughout the published literature [48]. Symptomatic use of expectorants is recommended to ease cough in cases with production of viscous secretions (COPD and bronchiectasis). Many patients also report positive subjective effectiveness using self-medication for acute bronchitis.

Combination phytotherapeutics can reduce the duration of acute cough of the common cold $[49,50]$.

In cystic fibrosis bronchiectasis, inhaled dornase- $\alpha$ eases cough

Inhalative anticholinergics (i.e. ipratropium and tiotropium) are thought to reduce mucus

\section{Learning points 3}

- Cough-variant asthma with BHR or eosinophilic bronchitis are responsive to inhaled corticosteroids.

- If gastro-oesophageal reflux-related cough is suspected, evaluate doubledose proton pump inhibitor treatment for a period of 2-3 months to alleviate cough.

- If a patient with chronic cough is using an ACE inhibitor, stop or replace their treatment for 3 weeks before starting further diagnostic workup (an exception from the rule), even if other causes for the cough are suspected.

\section{Learning points 4}

- First, consider causal treatment of the patient with cough if possible. If not, prescribe symptomatic treatment or the onset of the effect is delayed.

- Consider physiotherapy and/or physiotherapeutic equipment for troublesome productive and nonproductive cough with or without bronchiectasis, even if there is no or only low-grade evidence for efficacy.

- If there is a positive patientreported effect, consider expectorants in bronchiectasis and COPD patients.

- Chronic idiopathic cough and cough in palliative medicine: consider offlabel treatments (morphine or local anesthetics, such as lidocaine or low-dose amitryptiline).

production; however, their antitussive effect is not consistent [51].

Theophylline and $\beta_{2}$-adrenergics do increase mucociliary clearance, but are not effective relieving cough.

By "coating" cough receptors in the throat, demulcents are thought to have an antitussive effect. Cough syrups, lozenges and drops, and honey share sugar as a common ingredient. Effectiveness, if any, is limited in time to the contact of the sugar with the receptor, which is usually 20-30 min.

Systemic $\alpha$-adrenergics for nasal decongestion are popular in the US, but are virtually not in use in Germany and other parts of Europe. Fixed combinations with older, anticholinergic and central effective antihistamines (i.e. clorpheniramine or dexbrompheniramine) are not readily available in Europe. Moreover, evidence for 
their efficacy from randomised controlled trials is lacking.

Antibiotics are only effective against cough caused by a bacterial infection, characterised by purulent phlegm (i.e. suppurative bronchitis, bronchiectasis, exacerbation of COPD, purulent rhinitis and sinusitis). Antibiotics are not indicated in acute bronchitis.

Inhalative and nasal corticosteroids, and oral leukotriene antagonists alleviate cough in asthma, eosinophilic bronchitis, postinfectious cough due to $\mathrm{BHR}$, and rhinitis.

Local anaesthetics disable electrophysiological activity in the receptors and afferent nerves (e.g. during bronchoscopy). They are increasingly used offlabel for idiopathic cough and in palliative medicine [52].

Drugs affecting central mechanism for cough (antitussives) include systemically applied morphine or codeine, as well as natural and synthetic derivatives (i.e. dextromethorphan, dihydrocodeine, noscapine and pentoxyverin). Some nonaddictive herbal remedies (thyme, ribwort and sundew) claim central antitussive properties, though this is not proven by clinical studies. Opiates are recommended for effective symptomatic treatment of dry debilitating cough [53]. They have limited efficacy in the treatment of cough resulting from common cold [54].

\section{References}

1. Kardos P, Berck H, Fuchs KH, et al. Guidelines of the German Respiratory Society for diagnosis and treatment of adults suffering from acute or chronic cough. Pneumologie 2010 [Epub ahead of print D0I: 10.1055/s-00301255526].

2. Widdicombe JG. Neurophysiology of the cough reflex. Eur Respir J 1995; 8: 1193-1202.

3. Kohler D. Physiologie und Pathophysiologie des Hustens [Physiology und Pathophysiology of cough]. Pneumologie 2008; 62(Suppl. 1): S14-S17.

4. Irwin RS. Introduction to the diagnosis and management of cough: ACCP evidence-based clinical practice guidelines. Chest 2006; 129: 25S-27S.

5. Morice AH, Fontana GA, Sovijarvi AR, et al. The diagnosis and management of chronic cough. Eur Respir J 2004; 24: 481-492.

6. Kohno S, Ishida T, Uchida Y. The Japanese Respiratory Society guidelines for management of cough. Respirology 2006; 11: S135-S185.

7. Kardos P, Berck H, Fuchs KH, et al. Leitlinie der Deutschen Gesellschaft für Pneumologie und Beatmungsmedizin zur Diagnostik und Therapie von erwachsenen Patienten mit akutem und chronischem Husten [Guidelines of the German Respiratory Society for diagnosis and treatment of adults suffering from acute or chronic cough]. Pneumologie 2010; 64: 336-373.

8. Irwin RS, Rosen MJ, Braman SS. Cough. A comprehensive review. Arch Intern Med 1977; 137: 1186-1191.

9. Ing AJ, Ngu MC, Breslin AB. Pathogenesis of chronic persistent cough associated with gastroesophageal reflux. Am J Respir Crit Care Med 1994; 149: 160-167.

10. Kardos P, Gebhardt T. Chronisch persistierender Husten (CPH) in der Praxis: Diagnostik und Therapie bei 329 Patienten in 2 Jahren [Chronic persistent cough in general practice: diagnosis and therapy in 329 patients over the course of 2 years]. Pneumologie 1996; 50: 437-441.

11. Heikkinen T, Järvinen A. The common cold. Lancet 2003; 361: 51-59.

12. Interdisziplinäre Arbeitsgurppe "Allergische Rhinitis" der Sektion HNO. Allergische Rhinokonjunktivitis. Leitlinie der Deutschen Gesellschaft für Allergologie und klinische Immunologie [Interdisciplinary Task Force "Allergic Rhinitis" of the Section Otolaryngology Allergic Rhinoconjunctivitis. Guidelines of the German Society Allergology and Clinical Immunology]. Allergo J 2003; 12: 182-194.

13. Stein PD, Willis PW, DeMets DL. History and physical examination in acute pulmonary embolism in patients without preexisting cardiac or pulmonary disease. Am J Cardiol 1981; 47: 218-223.

14. Brunnee T, Graf K, Kastens B, et al. Bronchial hyperreactivity in patients with moderate pulmonary circulation overload. Chest 1993; 103: 1477-1481.

15. Pison C, Malo JL, Rouleau JL, et al. Bronchial hyperresponsiveness to inhaled methacholine in subjects with chronic left heart failure at a time of exacerbation and after increasing diuretic therapy. Chest 1989; 96: $230-235$.

16. Brandon N. Premature atrial contraction as an etiology for cough. Chest 2008; 133: 828.

17. Abouzgheib W, Pratter MR, Bartter T. Cough and asthma. Curr Opin Pulm Med 2007; 13: 44-48.

18. Johnson D, Osborn LM. Cough variant asthma: a review of the clinical literature. J Asthma 1991; 28 : 85-90.

19. Irwin RS, Curley FJ, French CL. Chronic cough. The spectrum and frequency of causes, key components of the diagnostic evaluation, and outcome of specific therapy. Am Rev Respir Dis 1990; 141: 640-647.

20. Palombini BC, Villanova CA, Araújo E, et al. A pathogenic triad in chronic cough: asthma, postnasal drip syndrome, and gastroesophageal reflux disease. Chest 1999; 116: 279-284.

21. McGarvey LP, Heaney LG, Lawson JT, et al. Evaluation and outcome of patients with chronic non-productive cough using a comprehensive diagnostic protocol. Thorax 1998; 53: 738-743.

22. Berg P, Wehrli R, Medici TC. Asthmahusten. Das monosymptomatische Bronchialasthma in Form von chronischem Husten[Asthmatic Cough. Monosymptomatic Bronchial Asthma In the form of a chronic cough]. Dtsch Med Wochenschr 1986; 111: 1730-1731.

23. Connell EJ, Rojas AR, Sachs MI. Cough-type asthma: a review. Ann Allergy 1991; 66: 278-285.

24. Frans A, Van Den Eeckhaut J. Cough as the sole manifestation of airway hyperreactivity. J Laryngol Otol 1989; 103: 680-682. 
25. Gibson PG, Dolovich J, Denburg J, et al. Chronic cough: eosinophilic bronchitis without asthma. Lancet 1989; 1: $1346-1348$.

26. Gibson PG, Hargreave FE, Girgis-Gabardo A, et al. Chronic cough with eosinophilic bronchitis: examination for variable airflow obstruction and response to corticosteroid. Clin Exp Allergy 1995; 25: 127-132.

27. Lee JJ, Lin RL, Chen CH, et al. Clinical manifestations of bronchogenic carcinoma. J Formos Med Assoc 1992; 91: $146-151$.

28. Corsico AG, Villani S, Zoia MC, et al. Chronic productive cough in young adults is very often due to chronic rhinosinusitis. Monaldi Arch Chest Dis 2007; 67: 90-94.

29. Dt.Ges.f.Hals-Nasen-Ohren-Heilkunde KuH-C Leitlinie Reizhusten / Räusperzwang Erwachsene (Klinischer Algorithmus) [German Society for Otolaryngology. Guideline dry cough / throat clearing. Adults. (Clinical Algorithm)]. HNO-Mitteilungen 1997; 47: 6S.

30. Morice AH, Fontana GA, Belvisi MG, et al. ERS guidelines on the assessment of cough. Eur Respir J 2007; 29: 12561276.

31. Christopher KL, Wood RP, Eckert RC, et al. Vocal-cord dysfunction presenting as asthma. N Engl J Med 1983; 308: $1566-1570$.

32. Schnatz PF, Castell JA, Castell DO. Pulmonary symptoms associated with gastroesophageal reflux: use of ambulatory $\mathrm{pH}$ monitoring to diagnose and to direct therapy. Am J Gastroenterol 1996; 91: 1715-1718.

33. Ours TM, Kavuru MS, Schilz RJ, et al. A prospective evaluation of esophageal testing and a double-blind, randomized study of omeprazole in a diagnostic and therapeutic algorithm for chronic cough. Am J Gastroenterol 1999; 94: 3131-3138.

34. Novitsky YW, Zawacki JK, Irwin RS, et al. Chronic cough due to gastroesophageal reflux disease: efficacy of antireflux surgery. Surg Endosc 2002; 16: 567-571.

35. Fuchs KH, Fischbach W, Labenz J, et al. [Topic complex VII: surgical therapy]. Z Gastroenterol 2005; 43: 191-194.

36. Israili ZH, Hall WD. Cough and angioneurotic edema associated with angiotensin-converting enzyme inhibitor therapy. A review of the literature and pathophysiology. Ann Intern Med 1992; 117: 234-242.

37. Martin L, Gustaferro C. Chronic cough associated with subacute bacterial endocarditis. Mayo Clin Proc 1995; 70 : $662-664$.

38. Stec S, Dabrowska M, Zaborska B, et al. Premature ventricular complex-induced chronic cough and cough syncope. Eur Respir J 2007; 30: 391-394.

39. Niimi A, Kihara Y, Sumita Y, et al. Cough reflex by ventricular premature contractions. Int Heart J 2005; 46: $923-$ 926.

40. Pitts T, Bolser D, Rosenbek J, et al. Impact of expiratory muscle strength training on voluntary cough and swallow function in Parkinson disease. Chest 2009; 135: 1301-1308.

41. Schönhofer B, Voshaar T, Köhler D. Long-term lung sequelae following accidental chlorine gas exposure. Respiration 1996; 63: 155-159.

42. Bonnet R, Jorres R, Downey R, et al. Intractable cough associated with the supine body position. Effective therapy with nasal CPAP. Chest 1995; 108: 581-585.

43. Imaizumi $\mathrm{H}$, Kaneko M, Mori K, et al. Reversible acquired tracheobronchomalacia of a combined crescent type and saber-sheath type. J Emerg Med 1995; 13: 43-49.

44. Chan KKY, Ing AJ, Laks L, et al. Chronic cough in patients with sleep-disordered breathing. Eur Respir J 2010; 35 : 368-372.

45. McGarvey LP . Does idiopathic cough exist? Lung 2008; 186(Suppl. 1): S78-S81.

46. Altiner A, Wilm S, Daubener W, et al. Sputum colour for diagnosis of a bacterial infection in patients with acute cough. Scand J Prim Health Care 2009; 27: 70-73.

47. Bott J, Blumenthal S, Buxton M, et al. Guidelines for the physiotherapy management of the adult, medical, spontaneously breathing patient. Thorax 2009; 64: Suppl. 1, i1-i51.

48. Rubin BK. Mucolytics, expectorants, and mucokinetic medications. Respir Care 2007; 52: 859-865.

49. Kemmerich B, Eberhardt R, Stammer H. Efficacy and tolerability of a fluid extract combination of thyme herb and ivy leaves and matched placebo in adults suffering from acute bronchitis with productive cough. A prospective, double-blind, placebo-controlled clinical trial. Arzneimittelforschung 2006; 56: 652-660.

50. Kemmerich B. Evaluation of efficacy tolerability of a fixed combination of dry extracts of thyme herb and primrose root in adults suffering from acute bronchitis with productive cough. A prospective, double-blind, placebocontrolled multicentre clinical trial. Arzneimittelforschung 2007; 57: 607-615.

51. Bolser DC. Cough suppressant and pharmacologic protussive therapy: ACCP evidence-based clinical practice guidelines. Chest 2006; 129: 238S-249S.

52. Lingerfelt BM, Swainey CW, Smith TJ, et al. Nebulised lidocaine for intractable cough near the end of life. J Support Oncol 2007; 5: 301-302.

53. Morice AH, Menon MS, Mulrennan SA, et al. Opiate therapy in chronic cough. Am J Respir Crit Care Med 2007; 175: 312-315.

54. Kardos P. Stellenwert chemisch-synthetischer Antitussiva und Expektorantien [The Value of Synthetized Antitussives and Expectorants]. Pharm Unserer Zeit 2008; 37: 472-476. 